\title{
VIGILÂNCIA EM SAÚDE DO TRABALHADOR: PASSOS PARA UMA PEDAGOGIA
}

\author{
SURVEILLANCE IN OCCUPATIONAL HEALTH: STEPS TOWARD A PEDAGOGY
}

\author{
Luiz Carlos Fadel de Vasconcellos ${ }^{1}$ \\ Carmen Verônica Barbosa de Almeida ${ }^{2}$ \\ Dimitri Taurino Guedes ${ }^{3}$
}

Resumo A Vigilância em Saúde do Trabalhador (Visat) compõe um conjunto de práticas legalmente inscritas no Sistema Único de Saúde (SUS) e recomendadas pelas diretrizes políticas que tratam das relações saúde-trabalho no Brasil. Entretanto, a Visat ainda é inusual e, quando existe, depende de atitudes voluntaristas de alguns profissionais no nível dos serviços. Afora a omissão gerencial do sistema de saúde para a sua implementação, uma das razões para que isso ocorra é a falta de capacitação técnica de agentes públicos para efetuá-la. O artigo trata de uma proposta metodológica para a capacitação em Vigilância em Saúde do Trabalhador, a partir de experiências desenvolvidas há alguns anos, no campo de ensino em serviço. Para isso, são discutidas as bases teórico-conceituais que norteiam a construção do campo da saúde do trabalhador e a pedagogia problematizadora utilizada no processo de educação permanente do SUS.

Palavras-chave saúde do trabalhador; vigilância em saúde; educação permanente; educação problematizadora.
Abstract Surveillance in Occupational Health (Visat) comprises a set of practices legally entered in the National Health System (SUS) and recommended by the policy guidelines that address the health-work relations in Brazil. However, the Visat is still uncommon and, when available, depends on proactive attitudes of some professionals at the service level. Aside from the failure of the management of the health system to implement Visat, another reason it is not implemented is the lack of technical capacity of public officials. The article presents a methodological proposal for the training of Surveillance in Occupational Health using experiences developed some years ago in the field of education in services. We discuss the theoretical and conceptual foundations that guide the development of the field of occupational health and the problem-based pedagogy used in the process of continuous education of the SUS.

Keywords occupational health; health surveillance; education; problem-based education. 


\section{Introdução}

A ruptura com o modelo centrado na doença, que levou ao desenvolvimento de uma doutrina que fundamenta a criação do Sistema Único de Saúde (SUS), consolidou a vigilância em saúde como a principal estratégia de contra-hegemonia a um sistema que ainda vê a medicina e o hospital como a 'solução final' dos problemas de saúde. Para ser coerente com o SUS, portanto, a vigilância deveria ser entendida como um de seus alicerces de construção e valorizada como um dos pilares de suas práticas cotidianas no nível dos serviços.

O entendimento de que a vigilância em saúde centra suas ações na prevenção dos danos e na promoção da saúde, atuando sobre alguns de seus fatores determinantes, consigna-a como o aparato típico do Estado, por intermédio de ações de natureza pública interventora (vigilância sanitária), mais potencialmente capaz de elevar os níveis de saúde da população e, portanto, de consolidar o próprio SUS em sua missão reformadora.

No mundo ocidental, dentro da lógica que construiu o Estado moderno, a vigilância sanitária é, sem dúvida, uma das áreas que se convencionou chamar de funções típicas do Estado. Sua tarefa de mediatizar, técnica e politicamente, os interesses dos diversos segmentos sociais na definição dos regulamentos e usar de poder coercivo para fazer cumpri-los é intransferível (Lucchese, 2001, p. 52).

Fundamentado no ideário filosófico e ideológico que sustenta a contrahegemonia ao modelo clássico centrado na doença, o SUS se pauta em bases organizacionais e legais, regidas pelos seus conhecidos princípios doutrinários: universalidade, integralidade e equidade, ratificados pelo artigo 198 da Constituição brasileira de 1988.

O fundamento organizacional emerge da necessidade do aparelho de Estado conferir concretude à base doutrinária, pela via da institucionalização das ações e serviços de saúde. Para que se concretize a institucionalidade da base organizacional de modo que viabilize a doutrina no mundo real, o movimento de construção do SUS exige um aparato legal capaz de legitimar na força da lei as aspirações e desejos constituintes de seu ideário.

Nesse contexto, a vigilância em saúde, seguindo o mesmo itinerário, é balizada pela doutrina, organização e legalidade do SUS, onde está abrigada. Mesmo assim, o exercício da vigilância em saúde, no campo institucional, ainda exibe lacunas no alcance de suas ações, contrariando a doutrina da universalidade, e muitas dificuldades de articulação entre seus componentes estruturais (vigilância epidemiológica e sanitária), que se mantêm separados, de modo incoerente com a idéia de uma vigilância totalizadora calcada na doutrina da integralidade.

A par dessa divisão histórica, existe ainda uma fragmentação da vigilância sanitária, em si mesma, em vários setores compartimentados, cujas ações são 
efetuadas por especialistas sobre objetos específicos - medicamentos, animais, serviços de saúde, alimentos, entre outros. Mais uma vez, observa-se uma ordem incompreensível num contexto doutrinário que fala em integralidade.

Recentemente, a essa divisão histórica da própria vigilância sanitária vem se agregando, em alguns serviços, a vigilância em saúde do trabalhador (Visat), por força de sua inclusão como campo de práticas do SUS.

O que antes já era um problema estrutural, agravou-se com a segmentação maior de atividades, as decorrentes especializações e a maior pulverização de ações. O desafio de se enfrentar uma vigilância cada vez menos integralizadora, contrariando a doutrina do sistema de saúde, passou a depender de uma revisão de seus modos de gestão, organização e mudança de modelo.

A superação dessa fragmentação tem duas faces: uma bem simples, baseada na decisão política de provocar a reengenharia administrativa, e uma bastante complexa, baseada na decisão política de favorecer cenários para a mudança da cultura institucional. A complexidade da segunda medida implica na mudança para o paradigma de vigilância em saúde, que depende da revisão de perfis profissionais e da implementação ostensiva de novos mecanismos de formação, reciclagem e educação permanente. Depende, ainda, de que a mudança de cultura institucional transponha o setor saúde, propriamente dito, e alcance o plural: mudança de culturas institucionais nas áreas de interesse da saúde (Vasconcellos, 2007, p. 270).

Quando, com a criação do SUS, a incorporação do campo da saúde do trabalhador surgiu como prática componente da vigilância em saúde, emergiu o desafio de se ampliar o olhar sobre as relações saúde-trabalho nas práticas cotidianas da vigilância sanitária. Reforçou esse desafio a preponderância de dispositivos constitucionais nos estados brasileiros relacionados à fiscalização dos processos e ambientes de trabalho, demonstrando a intencionalidade de conferir ao SUS essa nova prerrogativa.

$\mathrm{O}$ atributo mais frequentemente assinalado nas constituições estaduais (dez citações) diz respeito às fiscalizações/inspeções dos ambientes de trabalho. Reflete, sem dúvida, a intenção de conferir ao Sistema Único de Saúde a responsabilidade de intervir nos processos de trabalho, segundo o prisma da saúde pública, como contraponto à fiscalização tradicional, exercida pelo Ministério do Trabalho. É muito provável que o legislador tenha refletido a crítica que se faz à metodologia tradicional de intervenção, cujos resultados têm sido, há muito, questionados (Oliveira et al., 1997, p. 432).

Fica patente que a introdução da Visat no âmbito do SUS expressou o desejo de implementar a capacidade interventora do Estado, numa perspectiva distinta da intervenção tradicional, focada pontualmente no trabalho 
em si mesmo. O resgate da vigilância em saúde do trabalhador pelo campo de ação da saúde pública intencionou considerar os diversos determinantes sociais envolvidos com a relação da saúde com o consumo, o trabalho, o meio ambiente e até mesmo com o desenvolvimento. Nesse contexto, a incorporação de uma vigilância de processos produtivos (Vasconcellos, 2007), partindo da vigilância em saúde do trabalhador já instituída, configura uma maior integralização do olhar da vigilância sanitária sobre os complexos produtivos, onde repousa grande parte das fontes de adoecimento da população.

Desde a promulgação da Constituição Federal, das constituições estaduais logo a seguir e da Lei Orgânica da Saúde, em 1990, várias iniciativas foram sendo tomadas para institucionalizar a vigilância em saúde do trabalhador no âmbito do SUS (Vasconcellos, 2007, p. 281).

Fato relevante para a institucionalidade da Visat foi a emissão, em 1 de julho de 1998, da portaria MS n. ${ }^{\circ} 3.120$ (Instrução Normativa de Vigilância em Saúde do Trabalhador no SUS), cujo propósito era

fornecer subsídios básicos para o desenvolvimento de ações de Vigilância em Saúde do Trabalhador (...) instrumentalizar (...) os setores responsáveis pela vigilância e defesa da saúde, nas Secretarias de Estados e Municípios, de forma a incorporarem em suas práticas mecanismos de análise e intervenção sobre os processos e os ambientes de trabalho (Brasil, 1998, p. 2).

Embora a portaria MS n. ${ }^{0} 3.120 / 98$ traga um conjunto de informações fundamentais para o desencadeamento de ações de Visat, a forma de aplicabilidade das recomendações expostas não considera a adoção de um eixo pedagógico que seja capaz de traduzir as suas determinações na prática concreta das ações.

Assim, este trabalho partiu da hipótese de que não existe uma metodologia consolidada de capacitação, em consonância com os princípios da Visat no SUS, voltada para profissionais de vigilância em saúde e representantes de categorias de trabalhadores.

A proposta de criação de um eixo pedagógico foi baseada em capacitações de Visat que vêm sendo efetuadas há vários anos, em vários estados brasileiros, cuja observação empírica denota sua adequação ao campo da saúde do trabalhador (Vasconcellos, 2007, p. 289; p. 292).

Para tanto, definiram-se as bases teórico-conceituais a serem utilizadas no eixo pedagógico, tais como aquelas oriundas do Movimento Operário Italiano, de onde emerge o próprio conceito de saúde do trabalhador, e aquelas relacionadas à educação problematizadora, hoje, utilizada como paradigma da educação permanente do SUS; avaliaram-se aspectos relevantes que sobressaíram nos cursos já realizados; e, por fim, descreve-se a metodologia proposta com base nessas observações. 


\section{Base teórico-conceitual de uma pedagogia para a Visat ampliada}

O conceito de saúde do trabalhador, inscrito na Constituição Federal de 1988, encerra um contingente simbólico de contra-hegemonia nas relações saúde-trabalho, que acompanha o ideário reformador do movimento sanitário. Essa expressão simbólica que emergiu do campo de lutas desenvolvido na Itália, principalmente nos anos 1960 e 1970, pelo Movimento Operário Italiano, centrava-se na atitude pró-ativa dos trabalhadores pela conquista de sua saúde, tornando-os sujeitos 'protagônicos' desse processo.

Baseado em princípios de organização e ação, o movimento operário fundou uma desobediência aos cânones estabelecidos nas clássicas medicina do trabalho e saúde ocupacional, considerando que a saúde no trabalho não se vende nem se delega, defende-se (Alonso, 2007). Seus princípios consagrados dizem respeito à valorização do saber operário acumulado (experiênciasubjetividade), à não delegação da produção de conhecimentos, cujo processo se dá a partir da construção de mapas de risco por grupos homogêneos de trabalhadores e à validação consensual das informações, conjugando o saber profano (operário) e o saber técnico legitimado pela ciência oficial e, portanto, envolto numa certa sacralização.

Se establece una relación dialéctica entre el conocimiento experto y el conocimiento profano, basado en el principio de consenso entre ambos: "validación consensual". El criterio de aceptabilidad o no de determinadas situaciones de riesgo, así como las medidas preventivas a adoptar ha de ser consensuado. No se privilegia la opinión de un técnico sobre el grupo de trabajadores ni lo contrario. Era necesario el consenso (Alonso, 2007, p. 19).

O modelo operário, ao possibilitar a reconstrução dos processos de trabalho, identificando riscos e danos aos quais os trabalhadores estão expostos, recoloca os processos produtivos como protagonistas da vida social e, como espaços de enfrentamento extrapolados, alcança o cotidiano da população a partir de uma visão de mundo sistêmica. Enfim, revela "aquilo que as portas das fábricas tratam de tornar inviolável: as condições em que os trabalhadores produzem a riqueza social e têm suas vidas consumidas" (Facchini et al., 1991, p. 399).

O tom pedagógico mais relevante do movimento operário e, por conseguinte, da herdeira área de saúde do trabalhador no contexto brasileiro é a produção de conhecimentos validada consensualmente entre trabalhadores e técnicos. Laurell e Noriega (1989), a despeito da crítica ao modelo, ressaltam esse caráter pedagógico.

A inovação do Modelo Operário não consiste, pois, numa visão diferente da relação entre o trabalho e a saúde, mas naquilo que muda a lógica do processo de 
produção de conhecimentos relativos. Desta maneira, o sujeito e o condutor do processo de investigação não é o cientista, mas o grupo operário homogêneo auxiliado pelos especialistas (Laurell e Noriega, 1989, p. 87).

O movimento operário italiano tem sido considerado, especialmente no Brasil, como um marco referencial para a mudança do modelo de intervenção do Estado sobre as relações saúde-trabalho. Sua concepção revolucionária, que influenciou a criação do campo brasileiro de saúde do trabalhador, é valorizada no seu aspecto de organização e luta. Entretanto, o aspecto pedagógico inserido na sua base conceitual não tem sido devidamente observado e, tampouco, valorizado.

Ao tratar de uma nova pedagogia de formação e de construção de conhecimentos, o modelo pode ser capaz de redirecionar a formulação de políticas públicas educativas voltadas para as relações saúde trabalho.

Recentemente, Oddone (2007), um dos ideólogos e militantes do movimento operário italiano, em entrevista à publicação Salud, Trabajo y Medio Ambiente, ilustrou esse aspecto pedagógico do movimento.

Teníamos que construir un lenguaje nuevo, que pudiera servir como interfaz entre, por un lado, la representación de la condición laboral de parte de los obreros y, por el otro, el conocimiento de la comunidad científica médica, que abstraía de los puestos de trabajo concretos, porque no los conocía. Tuvimos que inventar la técnica de las "instrucciones al socio". Se trataba de dar las instrucciones sobre aquello que se hacía, respondiendo a la siguiente propuesta: "Para que yo sea como tú; imagina que yo tenga que sustituirte en tu trabajo de manera que nadie se dé cuenta de que no eres tú" (Oddone, 2007, p. 6).

Segundo o próprio Oddone, o processo protagonizado pelos trabalhadores concorre para a construção de um conhecimento científico, especialmente pela abertura de novas janelas de conhecimento. Sobre o tema, Oddone relata o depoimento de um operário sobre a linguagem científica acerca das doenças do trabalho, em que este assinalava o erro de se considerar a linguagem médica corrente como a única validada pela ciência. O operário argumentava que a doença do trabalho "era algo que cada uno veía desde su 'ventana hacia el patio', donde esta figurativamente se encontraba. (...) Las ventanas son muchas; muchos los lenguajes y los conocimientos que requieren" (Oddone, 2007, p. 7).

Nessa linha, conclui Oddone: "Es así que comprendí, - y estoy cada vez más convencido de ello-, que las situaciones laborales concretas bien conocidas por los obreros comprometidos forman parte esencial de los conocimientos científicos" (Oddone, 2007, p. 8).

A vigilância em saúde do trabalhador se situa no centro do debate inaugurado pelo movimento operário, por tratar de um novo conhecimento- 
uma nova janela - no sentido de aplicar a doutrina do sistema de saúde brasileiro às transformações do mundo do trabalho. Se nem a vigilância epidemiológica e a vigilância sanitária estão preparadas para olhar por essa janela, o papel da formação de seus quadros ganha em relevância pela possibilidade de instituir novos cenários, novas paisagens.

O princípio da participação da comunidade (controle social) do SUS adiciona um ingrediente facilitador na institucionalização dessa vigilância, quando legitima a inclusão de forma real e ativa dos sujeitos, no caso os trabalhadores, enquanto atores do processo metodológico para atuar na Visat. Considerando que a construção de um novo campo de conhecimentos, conjugando saberes profanos e 'sacros', é uma condição fundante para a vigilância das relações saúde-trabalho, o controle social do SUS é a senha de permissão para uma ousadia reformuladora da formação dos agentes públicos de vigilância.

A portaria $n{ }^{\circ}{ }^{0} 3.120 / 98$ ratifica essa compreensão no subitem 3.4:

Controle social: incorporação dos trabalhadores e das suas organizações, principalmente as sindicais, em todas as etapas da vigilância em saúde do trabalhador, compreendendo sua participação na identificação das demandas, no planejamento, no estabelecimento de prioridades e adoção de estratégias, na execução das ações, no seu acompanhamento e avaliação e no controle da aplicação de recursos (Brasil, 1998, p. 3).

Observa-se no texto normativo uma radicalização do processo participativo, em que o controle social supera o seu papel clássico de atuar "na formulação de estratégias e no controle da execução da política de saúde" (Brasil, 1990, p. 1) na direção de uma participação política introjetada no corpo das ações e serviços do Estado, com uma significativa pedagogia implícita naquela proposição.

À semelhança do que se propunha como comunidade científica ampliada no movimento operário (Oddone et al., 1986, p. 11), a ação do controle social, nessa perspectiva, germina espaços compartilhados de poder político geradores de novos conhecimentos e, portanto, novas verdades.

Saviani (2008), em sua formulação pedagógica, considera que “a prática política apoia-se na verdade do poder; a prática educativa, no poder da verdade" (Saviani, 2008, p. 87).

Considerando-se a intervenção da vigilância em saúde como uma prática política, há uma nítida aproximação entre a pedagogia empírica do movimento operário e as pedagogias emancipatórias que colocam o sujeito-aprendiz como sujeito produtor de saber e agente político de transformação da realidade. Consumá-la nesses moldes é restabelecer o poder da verdade e imiscuí-la na prática política, por dentro do aparelho de Estado. 
Nesse contexto, uma aproximação necessária deve ocorrer entre o formato de preparação-capacitação dos agentes públicos interventores do SUS para a vigilância das relações saúde-trabalho, em comunidades ampliadas de intervenção com os próprios trabalhadores, e o modelo de preparaçãocapacitação de trabalhadores do SUS, proposto pela Política Nacional de Educação Permanente em Saúde, regulamentada pela portaria GM/MS n. ${ }^{\circ}$ 1996, de 20/08/2007.

Distinta da participação burocrática de formulação e controle, a idéia do controle social em saúde do trabalhador, legitimada pela normativa de vigilância (portaria n. ${ }^{\circ} 3.120 / 98$ ), ajusta-se à constituição de comunidades ampliadas de produção de conhecimentos, seguindo a formulação original do movimento operário, especialmente se for considerado que estão em jogo atitudes decisórias do Estado no ato de vigiar as relações saúde-trabalho.

A configuração de comunidades ampliadas de pares em processos decisórios, em que a ciência é convocada mas não alcança o grau requerido para solucionar os graus de incerteza, exigindo postulados de uma ciência pósnormal (Funtowicz e Ravetz, 1997), e o conceito de comunidade científica ampliada aplicada às atividades de trabalho e ao debate de normas (Schwartz, 2006) constituem-se em novas ferramentas metodológicas de ensino-aprendizagem que enriquecem a pedagogia problematizadora proposta na política de educação permanente do SUS.

A intenção reformadora do SUS na direção da mudança do modelo concentra a educação em saúde, grosso modo, em dois grandes eixos: o da educação para fora dos aparelhos da saúde, voltada para a população em geral (educação popular em saúde, especialmente conduzida na atenção básica); e o da educação para dentro do setor saúde propriamente dito (educação permanente de seus técnicos, investidos da missão de agentes de mudança do modelo).

Em ambos, há um eixo pedagógico comum inspirado em Paulo Freire, de cuja rica formulação pedagógica extrai-se o axioma da educação 'problematizadora' em oposição à clássica educação 'bancária', em que os alunos são como caixas de depósitos de conhecimentos dos educadores (Freire, 1987).

Na educação problematizadora, dita libertadora pelo próprio Freire, o educando (oprimido) passa a perceber criticamente o mundo que o oprime, desvela a realidade e o coloca num permanente movimento de busca de "ser mais", consciente de sua inconclusão: o homem como ser inconcluso (Freire, 1987).

Com palavras e interpretações distintas, a pedagogia do movimento operário caminha por trilhas similares: o trabalhador como ser inconcluso no mundo do trabalho, educando e educador ao mesmo tempo, para libertar-se da opressão que o faz apêndice da máquina, engrenagem 'aistórica' de um processo que lhe tritura sem controle e sem piedade. No movimento operário, rebelar-se através de uma pedagogia libertadora é transpor-se ao seu devir histórico de 'ser mais'. 
O método freiriano fundado no diálogo educador-educando encerra, contudo, o dilema do agente educador, cujo compromisso ideológico não é suficiente para superar o modelo educativo tradicional. Freire propõe o enfrentamento desse desafio de desenvolver uma capacidade dialógica do educador, a partir de conteúdos programáticos com temas geradores do universo temático dos educandos (Freire, 1987).

A analogia com a pedagogia implícita da vigilância em saúde do trabalhador é evidente, especialmente pela eclosão de temas geradores nas demandas identificadas pelos trabalhadores na metodologia de intervenção, conforme a perspectiva de controle social do SUS estabelecida na norma de vigilância. É o cenário pedagógico adequado para as iniciativas de mudança das relações saúde-trabalho ampliadas, especialmente porque se abordariam, simultaneamente, os dois eixos de educação do SUS - o da educação popular e o da educação permanente.

O movimento de alfabetização de adultos com base nas palavras do mundo, mote inaugural da pedagogia freiriana, e o movimento de 'alfabetização' dos operários, com base nas palavras do mundo do trabalho - os riscos à saúde da primeira ronda -, são gemelares em intenções, significados, ideologia, esperança. Por que, por tanto tempo, estas necessárias aproximações têm estado tão distanciadas?

De todo modo, em virtude de se estar buscando um caminho pedagógico para agentes públicos de saúde, seus passos deverão estar de acordo com a política de educação permanente do SUS, até porque o que vai por aqui proposto é com ela coerente.

As bases conceituais que fundamentam o método freiriano e o modelo pedagógico do movimento operário são tangíveis aos princípios e diretrizes da política do SUS, especialmente em sua compreensão:

A educação permanente é a realização do encontro entre o mundo da formação e o mundo do trabalho, onde o aprender e o ensinar se incorporam ao cotidiano das organizações e ao trabalho. Propõe-se, portanto, que os processos de qualificação dos trabalhadores da saúde tomem como referência as necessidades de saúde das pessoas e das populações, da gestão setorial e do controle social em saúde e tenham como objetivos a transformação das práticas profissionais e da própria organização do trabalho e sejam estruturados a partir da problematização do processo de trabalho (Brasil, 2004, p. 1).

\section{Base operacional para uma Visat ampliada}

A portaria $n .^{\circ}$ 3.120/98, que rege a vigilância em saúde do trabalhador, exibe um roteiro operacional de implementação de ações, até certo ponto detalhado, 
mas não aponta o caminho pedagógico de formação dos agentes interventores, salvo por alguns indicativos. Entre estes, destaca-se a participação dos trabalhadores em todas as etapas de vigilância, da preparação ao acompanhamento da execução, inclusive na identificação das demandas.

Baseada na sequência de tópicos: conceituação básica; princípios; objetivos; estratégias; metodologia; e informações básicas, a portaria n. ${ }^{\circ}$ 3.120/98 é um marco normativo relevante para o desencadeamento de ações de vigilância, cuja incorporação ao cotidiano das práticas ainda não ocorreu, especialmente pela ausência de um processo massivo de formação de agentes públicos e sociais para esse fim.

A conceituação básica considera a amplitude dos fatores determinantes dos agravos, a intersetorialidade e a sua vinculação e dependência da vigilância em saúde como um todo.

Como princípios, tendo o SUS como modelo, são considerados: a universalidade, abrangendo todos os trabalhadores em qualquer situação; integralidade das ações, incluindo a assistência, a recuperação, a prevenção e a promoção; pluri-institucionalidade, cuja articulação em rede abrange instituições de consumo e ambiente; controle social, incorporação pró-ativa dos trabalhadores em todas as etapas da vigilância; hierarquização e descentralização, consolidação do município e distritos sanitários como instância de desenvolvimento das ações; interdisciplinaridade, integração do saber técnico de diferentes áreas do conhecimento com o saber operário; pesquisaintervenção, como processo contínuo de produção de conhecimentos, ao longo do tempo; e, finalmente, o caráter transformador dos processos e ambientes de trabalho superando, inclusive, a própria legislação.

Dentre os objetivos, enumeram-se os conhecimentos da realidade sanitária da população trabalhadora e de seus perfis históricos, dos riscos e cargas de trabalho, das novas formas de adoecer e morrer no trabalho; e a intervenção sobre os fatores determinantes de agravos, eliminando-os, atenuando-os ou controlando-os, por meio da fiscalização e da negociação coletiva, subsidiando decisões nas esferas do governo, para o estabelecimento de políticas públicas e aprimoramento das normas legais. Entre os objetivos está, ainda, a participação na formação, capacitação e treinamento de recursos humanos para a área.

Quanto às estratégias, destaca-se a vinculação institucional com as estruturas de vigilância, superando "a dicotomia existente em suas práticas, em que o objeto de ação da vigilância, em geral, não contempla o processo de produção e sua relação com a saúde dos trabalhadores" (Brasil, 1998, p. 4). Destaca-se, ainda, a adoção de intervenções de impacto, utilizando-se bases por critério de atuação (sindical, ramo produtivo, território, epidemiológico), de acordo com variáveis locais favorecedoras da intervenção.

A metodologia possui um caráter estratégico para o desenvolvimento da pedagogia que ora se propõe, em virtude de determinar que o desenvolvi- 
mento das ações se dê a partir de fase preparatória, efetuada por meio de análise conjunta dos técnicos com trabalhadores e representantes sindicais que conheçam a empresa ou setor de empresas - objeto da intervenção a ser realizada. Ainda, na metodologia, a norma enfatiza que a própria intervenção (inspeção/fiscalização sanitária) se realiza em conjunto com os representantes dos trabalhadores.

É nesse contexto metodológico da normativa de vigilância que surge a imperiosa necessidade de se desenvolver uma pedagogia capaz de responder ao desafio de preparação interativa e problematizadora de sujeitos interventores, no âmbito de uma real política de Estado no campo da saúde, associando objetos-sujeitos da política de intervenção (profissionais de vigilância) aos sujeitos-objetos da intervenção da política (trabalhadores).

A metodologia proposta na norma de vigilância aponta, ainda, para a necessidade de se analisar o processo produtivo e sua organização, efetuando

inquéritos, por meio da equipe interdisciplinar e de representantes sindicais e ou dos trabalhadores, aplicando questionários ao conjunto dos trabalhadores, contemplando a sua percepção da relação entre trabalho e saúde, a morbidade referida (sinais e sintomas objetivos e subjetivos), a vivência com acidente e o quase acidente de trabalho (incidente crítico), consigo e com os companheiros, e suas sugestões para a transformação do processo, do ambiente e das condições em que o trabalho se realiza (Brasil, 1998, p. 10).

Outras técnicas são invocadas na metodologia, inclusive o mapeamento de riscos, cuja origem remonta ao próprio movimento operário. O desenvolvimento de capacidades tecnológicas de análise, tais como a aplicação de árvore de causas para investigação de acidentes, a identificação de necessidades para se realizar estudos epidemiológicos e o acompanhamento do processo de intervenção, ao longo do tempo, são procedimentos metodológicos prescritos, cuja realização carece de uma capacitação básica e uma educação permanente dos agentes públicos e sociais envolvidos.

Na sequência de tópicos normativos, as informações básicas dizem respeito ao tratamento de dados de interesse para as ações, que permitam a análise e a intervenção sobre os fatores determinantes dos agravos. A norma define um elenco básico de informações e aponta para quaisquer outras de interesse, à medida que os sistemas de informações se estruturem e se consolidem. São partes do elenco: informações de morbidade e mortalidade disponíveis nos diversos sistemas, definição de eventos sentinelas, levantamentos de atividades e processos produtivos e resultados de pesquisas de interesse da área.

Analisando a vigilância em saúde do trabalhador ampliada como ponto de partida para uma política de Estado, Vasconcellos (2007) considera como parâmetros básicos para a configuração de uma vigilância dos processos 
produtivos e do desenvolvimento: o político-gerencial, o teórico-metodológico e o técnico-administrativo. O parâmetro político-gerencial seria "dado pela decisão de assumir uma política de Estado na área de saúde, trabalho e desenvolvimento sustentável, utilizando a capacidade sistêmica do SUS" (Vasconcellos, 2007, p. 288). O parâmetro teórico-metodológico estará fundamentado na portaria n. ${ }^{\circ} 3.120 / 98$, “cujo objeto de vigilância seria ampliado da saúde do trabalhador para os processos produtivos, com as adaptações e agregações necessárias" (Vasconcellos, 2007, p. 288). Já o parâmetro técnicoadministrativo, em que se considera a adoção de níveis de complexidade da ação, tem na capacitação dos agentes inseridos em diversos pontos da rede de atenção um aspecto estruturante fundamental para essa nova vigilância.

\section{Base metodológica de uma pedagogia para a Visat ampliada}

Os antecedentes da construção de uma pedagogia de vigilância em saúde do trabalhador resultam de demandas concretas por formação de agentes públicos com a institucionalização gradativa dos Programas de Saúde do Trabalhador, no decorrer dos anos 1990. Atuando como formuladores e instrutores de cursos de capacitação durante mais de 15 anos em demandas trazidas pela área técnica do Ministério da Saúde e pelas secretarias de saúde de vários estados e municípios brasileiros, foram ministrados cursos de Visat em várias unidades federativas: AL, AP, AM, DF, GO, MT, PA, PB, PE, PI, RJ, RN, RS, RO, RR, SC, SE e TO (Vasconcellos, 2007). Em alguns desses estados, o curso foi aplicado mais de uma vez na modalidade de formação básica ( $1^{\circ}$ nível) e, em outros, foi aplicada, também, a modalidade de formação de multiplicadores ( $2^{\circ}$ nível).

A criação de uma metodologia empírica, baseada em princípios do movimento operário e da problematização freiriana, foi se constituindo, pouco a pouco, nessas duas modalidades: básica, com atividade presencial de 40 horas; e formação de multiplicadores, com carga presencial de 80 horas (Vasconcellos, 2005).

A metodologia utilizada nessas capacitações propiciou, em alguns estados, desencadear ações de Visat que continuam acontecendo. Em outros estados, o método trouxe à tona evidências sobre as dificuldades para o desencadeamento de ações, localizadas principalmente nas esferas gerenciais e intersetoriais.

A experiência compartilhada nessas capacitações entre centenas de técnicos e trabalhadores pelo Brasil, nos últimos anos, constituiu-se num acervo considerável, do qual se vale para pensar os passos para uma pedagogia de vigilância.

A formação básica de $1^{\circ}$ nível é desenvolvida em horário integral, durante cinco dias úteis, sob a responsabilidade de dois instrutores facilitadores (ou multiplicadores). O aprendizado interativo entre alunos e instrutores tem 
por objetivo preparar uma ação de intervenção (vigilância com fiscalização/inspeção) sobre um alvo predeterminado, baseada na fase preparatória recomendada pela portaria $n .^{\circ} 3.120 / 98$, como foi visto.

A demanda (objeto-alvo da vigilância) é trazida pelos representantes sindicais alunos do curso e o ato fiscal é garantido pelos agentes públicos da vigilância sanitária, também alunos. É recomendado que a demanda seja dirigida a estabelecimentos capazes de provocar impacto para a categoria dos trabalhadores e sobre o setor econômico alvo (Vasconcellos, 1994; Vasconcellos e Ribeiro, 1997; Brasil, 1998).

O impacto, cujo objetivo é buscar um efeito exemplificativo, disciplinador e paradigmático sobre o setor econômico, pode considerar o porte da empresa (maior ou das maiores na região), relevância político-estratégica e/ou situações consideráveis de risco conhecidas ou potenciais. Uma vez justificada a demanda, e se aceita pelo grupo, inicia-se a preparação da ação (Vasconcellos, 2007, p. 290).

Com número máximo de 32 alunos, a turma é dividida em quatro equipes fiscais que preparam detalhada e minuciosamente a ação. Em cada equipe deve haver pelo menos dois agentes, com prerrogativas de fiscais sanitários, e pelo menos um representante de categoria de trabalhadores, sendo os demais técnicos distribuídos uniformemente, buscando compor interdisciplinarmente as quatro equipes. Cada uma delas fica responsável por um alvo predeterminado e sigiloso, para garantir o elemento surpresa da fiscalização do(s) estabelecimento(s), que normalmente é demandado por já possuir um histórico de problemas de saúde do trabalhador.

As equipes se reúnem separadamente para conhecer o processo de produção a ser fiscalizado, alternando atividades com as demais para apresentar os resultados de cada preparação. Em cada equipe, o representante sindical descreve a realidade do processo e ela esboça em papel, ou em computador, o layout os postos e setores de trabalho e as etapas dos processos. A explanação do representante dos trabalhadores viabiliza o conhecimento do ambiente e do processo de trabalho.

Na preparação da ação, em que são discutidas diversas variáveis, desde as razões da demanda à análise detalhada do processo, seus componentes tecnológicos, organizacionais, humanos, ambientais, os riscos e as relações de trabalho, entre outros, fica muito evidente a supremacia do saber operário na construção do conhecimento compartilhado sobre o objeto-alvo. Sem dúvida, sem a participação do trabalhador na equipe, o aprendizado se torna vazio de conteúdo e a ação proposta é preparada em bases inconsistentes quanto ao conhecimento sobre o objeto. Inclusive o entendimento é de que sem a participação de trabalhadores o curso fica inviabilizado, como já ocorreu em algumas ocasiões. 
Numa linha interdisciplinar são construídos fluxogramas de processo; inventários de atividades, insumos, máquinas e equipamentos; mapas de risco; check-lists; protocolos de análise ergonômica sumária; questionários de morbidade referida, incidentes críticos e percepção objetiva e subjetiva dos riscos e cargas de trabalho; inventários ambientais, entre outras variáveis.

As atividades de preparação da ação compõem a primeira etapa, com duração total de 24 horas (três dias úteis ou três jornadas de oito horas cada), antecedente à ação fiscal que ocorre no quato dia do curso. Durante a ação, a equipe, composta em média por oito agentes de fiscalização/ inspeção, previamente dividida, em que cada agente possui uma tarefa predeterminada pela própria equipe, efetua a inspeção, de acordo com o plano: examina documentos, entrevista gerentes, trabalhadores e pessoal da área de segurança e saúde, confere os fluxogramas de processo, os check-lists e os inventários e realiza mapeamento fotográfico, entre outras tarefas.

Finalmente, no quinto dia do curso, são apresentados os relatórios de cada uma das equipes dos quatro estabelecimentos distintos. As medidas a serem tomadas e o planejamento de continuidade da ação ao longo do tempo (Brasil, 1998) são debatidos e decididos consensualmente por toda a turma.

A formação básica de primeiro nível tem o objetivo de sensibilizar agentes públicos, profissionais que atuam na área e trabalhadores do controle social e de organizações sindicais, entre outras. Essa capacitação pretende

induzir à reflexão sobre as inter-relações entre os processos produtivos e a saúde dos trabalhadores; propiciar a apreensão de conceitos-chave de Visat; propiciar o conhecimento da legislação pertinente, [...] legislações locais e a Portaria 3.120/98; instruir para o desenvolvimento de metodologias de investigação/ intervenção; desencadear de imediato ações de baixa complexidade; identificar objetos de intervenção epidemiológica e sanitária em situações específicas; fomentar a integração dos níveis operacionais intrassetoriais do SUS com os níveis de representação sindical dos trabalhadores; e identificar multiplicadores, entre os alunos, para dar continuidade ao processo (Vasconcellos, 2007, p. 291).

Já a formação de segundo nível prepara os agentes multiplicadores identificados para ministrar o curso básico de primeiro nível. Na formação de multiplicadores aprofunda-se a reflexão sobre os processos produtivos, a saúde dos trabalhadores e os conceitos de Visat. A metodologia é direcionada para possibilitar um maior domínio da legislação (sanitária, trabalhista, previdenciária, ambiental e outras), o desenvolvimento de capacidades de discorrer e orientar metodologias de investigação e intervenção e agregar novos conhecimentos para o desencadeamento de ações. 
Nesse nível, as técnicas pedagógicas utilizadas são baseadas em dinâmicas de grupo e dramatizações sobre situações simuladas de casos, tais como audiências públicas, conflitos institucionais e encomendas de estudos.

\section{Conclusão}

O método freiriano dialógico educador-educando pretende capacitar as pessoas para detectar seus problemas reais e buscar soluções originais e criativas para elas. Ao valorizar a observação da realidade dialogada com a participação efetiva nas ações transformadoras das condições de vida e trabalho, a partir do processo ensino-aprendizagem, o resultado é o desenvolvimento de uma consciência crítica e reflexiva.

O olhar operário, nessa concepção pedagógica, é compreendido como categoria social de ação das classes populares pela conquista de seus direitos com maior capacidade de entendimento e enfrentamento de seus problemas.

E, ainda, a educação concebida dialogicamente, mediante a troca entre os saberes técnico-científico e popular, em que ambos ensinam e aprendem, produz novos conhecimentos e reorienta as ações de saúde.

Educação Permanente é o conceito pedagógico, no setor da saúde, para efetuar relações orgânicas entre ensino e as ações e serviços e entre docência e atenção à saúde, sendo ampliado, na Reforma Sanitária Brasileira, para as relações entre formação e gestão setorial, desenvolvimento institucional e controle social em saúde (Brasil, 2004, p. 2)

Nesse contexto, articulando as formulações do movimento operário com a educação permanente do SUS, a proposta de criação de novos espaços pedagógicos de formação para a vigilância em saúde está pronta para o uso mais sistemático.

Avaliações efetuadas ao longo dos anos, a partir de depoimentos dos alunos, demonstram aspectos relevantes desse método. Podem ser destacados: - o conhecimento adquirido é centrado igualmente no instrutor e no grupo;

- a ênfase é no campo da prática, mais do que na teoria, cujo resultado é a transformação da realidade;

- comparado a outras metodologias de capacitação, o método de ensino é considerado melhor e mais adequado para o desencadeamento de ações;

- o curso contempla na sua organização: controle social, intersetorialidade; interdisciplinaridade, transparência de informações, construção coletiva de conhecimento, participação de todo o grupo e de todos os alunos, oportunidade democrática de participação, conhecimentos técnicos e, entre outros, segurança para a ação;

- o método contribui para a mudança das práticas. 
O ponto-chave desse método é a capacitação conjunta dos agentes públicos com os trabalhadores, geralmente representantes sindicais, harmonizada tanto ao princípio do controle social do SUS, quanto fiel à idéia original do campo da saúde do trabalhador, que tem no trabalhador o sujeito ativo e central das ações, especialmente na vigilância (Ribeiro e Vasconcellos, 1995; Machado, 1996).

A longa experiência no desenvolvimento do método demonstrou alguns resultados significativos, como a superação da retórica da participação social, trazendo o elemento social para dentro do processo político e técnico, a ponto de influir no nível decisório. Outro aspecto é a desconstrução da hegemonia do saber técnico na condução das práticas, viabilizando "o empoderamento dos trabalhadores no policy-making" (Vasconcellos, 2007, p. 293).

Sua implementação mais ordenada e sistemática trará inevitáveis aprimoramentos e adaptações às distintas realidades locais. Fazer saúde e repensá-la impõe-se na variedade de contextos sociais, territoriais, econômicos e políticos, em que as práticas devem ser revistas permanentemente, revelando e relevando aspectos que influenciam e são influenciados historicamente nas dinâmicas sociais.

A rigor, se existe uma base conceitual de saúde do trabalhador que considera o trabalhador como sujeito central das práticas, se a base normativa referenda essa compreensão no aspecto da vigilância, cujo objeto é a intervenção sobre os objetos e transformação do mundo dos mesmos objetos, e se existe uma demanda político-institucional pela formação de agentes públicos nesse campo, a evidência soberana é de que é preciso construir uma base pedagógica articuladora desses elementos.

Uma releitura do movimento operário, em suas formulações de criação das comunidades ampliadas, e a maior apreensão da pedagogia de base freiriana constituem uma trilha fiel à doutrina do SUS, coerente com o seu ideário revolucionário, e harmonizada ao conceito da saúde do trabalhador.

A ampliação da base político-institucional de atuação sobre as relações saúde-trabalho, por seu turno, é uma exigência inevitável do andar instituinte da saúde, em sua visão calcada na integralidade e nas suas formulações de promoção e prevenção como esperanças de construção de um novo modelo. “Movo-me na esperança enquanto luto e, se luto com esperança, espero. Se o diálogo é o encontro dos homens para Ser Mais, não pode fazer-se na desesperança. Se os sujeitos do diálogo nada esperam do seu que fazer já, não pode haver diálogo" (Freire, 1987, p. 47).

Assim, é possível que a saúde do trabalhador, que já vem abrindo 'janelas para o pátio', se o fizer numa perspectiva ampliada, descortinará novas paisagens no horizonte de um outro modelo de saúde para o Brasil. 


\section{Notas}

1 Pesquisador da Escola Nacional de Saúde Pública Sergio Arouca, Fundação Oswaldo Cruz (Ensp/Fiocruz), Rio de Janeiro, Brasil. Doutor em Saúde Pública pela Ensp/Fiocruz. Correspondência: Rua Toneleros, 131, apto. 1002, Copacabana, Rio de Janeiro, RJ, Brasil, CEP 22030-000.<elfadel@globo.com>

2 Coordenadora do Centro de Referência Estadual de Saúde do Trabalhador do Estado da Paraíba (Cerest/PB), João Pessoa, Paraíba, Brasil. Mestre em Desenvolvimento e Meio Ambiente pela Universidade Federal da Paraíba (UFPB). <carmenvba@yahoo.com>

3 Professor da Faculdade de Ciências da Saúde do Trairi, da Universidade Federal do Rio Grande do Norte (Facisa/UFRN), Santa Cruz, Rio Grande do Norte, Brasil. Mestre em Engenharia de Produção pela Universidade Federal da Paraíba (UFPB).<dtaurino@ufrnet.br>

\section{Referências}

ALONSO, Ángel C. La salud no se vende ni se delega, se defiende: El modelo obrero. Madrid: Ediciones GPS, 2007.

BRASIL. Lei n. ${ }^{\circ} 8.142$, de 28 de dezembro de 1990. Dispõe sobre a participação da comunidade na gestão do Sistema Único de Saúde (SUS) e sobre as transferências intergovernamentais de recursos financeiros na área da saúde e dá outras providências. Diário Oficial da República Federativa do Brasil, Poder Executivo, Brasília, DF, 31 dez. 1990. Seção I, p. 25.694-25.695.

Ministério da Saúde. Portaria n. ${ }^{\circ} 3.120$, de 1 de julho de 1998. Aprova a instrução normativa de vigilância em saúde do trabalhador no SUS. Diário Oficial da República Federativa do Brasil, Poder Executivo, Brasília, DF, 14 jul. 1998. Seção I.

Ministério da Saúde. Portaria n. ${ }^{\circ} 198$, de 13 de fevereiro de 2004. Institui a política de educação permanente em saúde como estratégia do Sistema Único de Saúde para a formação e desenvolvimento de trabalhadores para o setor e dá outras providências. Diário Oficial da República
Federativa do Brasil, Poder Executivo, Brasília, DF, 15 fev. 2004. Seção I.

FACCHINI, Luiz A. et al. Modelo operário e percepção de riscos ocupacionais e ambientais: o uso exemplar de estudo descritivo. Revista de Saúde Pública, São Paulo, n. 25, v. 5, 1991.

FREIRE, Paulo. Pedagogia do oprimido. 17. ed. Rio de Janeiro: Paz e Terra, 1987.

FUNTOWICZ, Silvio O. e RAVETZ, Jerome R. Ciência pós-normal e comunidades ampliadas de pares face aos desafios ambientais. História, Ciências, Saúde - Manguinhos, Rio de Janeiro, v. IV, n. 2, p. 219-230, jul.-out. 1997.

LAURELL, Asa Cristina e NORIEGA, Mariano. Processo de produção e saúde: trabalho e desgaste operário. São Paulo: Hucitec, 1989.

LUCCHESE, Geraldo. Globalização e regulação sanitária: os rumos da vigilância sanitária no Brasil. Tese (Doutorado em Saúde Pública) - Rio de Janeiro: Escola Nacional de Saúde Pública Sergio Arouca, Fundação Oswaldo Cruz, 2001. 
MACHADO, Jorge M. H. A heterogeneidade da intervenção: alternativas e processos de vigilância em saúde do trabalhador. Tese (Doutorado em Saúde Pública) - Rio de Janeiro: Escola Nacional de Saúde Pública Sergio Arouca, Fundação Oswaldo Cruz, 1996.

ODDONE, Ivar et al. Ambiente de trabalho: a luta dos trabalhadores pela saúde. São Paulo: Hucitec, 1986.

ODDONE, Ivar. Reflexiones sobre el modelo obrero italiano: entrevista por Estela Ospina S. Revista Sindical de Salud, Trabajo y Medio Ambiente, n. 5, ano 2, p. 4-8. Lima, Peru: Instituto Laboral Andino, jun. 2007.

OLIVEIRA, M. H. Barros et al. Análise comparativa dos dispositivos de saúde do trabalhador nas constituições estaduais brasileiras. Cadernos de Saúde Pública, Rio de Janeiro, v. 13, n. 3, p. 425-433, 1997.

RIBEIRO, Fátima S. N.; VASCONCELLOS, L. C. Fadel. Controle social em saúde do trabalhador: a prática do discurso e o discurso na prática. In: CONGRESSO BRASILEIRO DE CIÊNCIAS SOCIAIS EM SAÚDE, 1. Curitiba: Abrasco, 1995.

SAVIANI, Dermeval. Escola e democracia: teorias da educação, curvatura da vara, onze teses sobre educação política. Campinas, São Paulo: Autores Associados, 2008.
SCHWARTZ, Yves. Entrevista. Trabalho, Educação e Saúde, Rio de Janeiro, v. 4 n. 2, p. 457-466, 2006.

VASCONCELLOS, L. C. Fadel. Os caminhos do caminho: a municipalização como estratégia de consolidação da saúde do trabalhador no setor saúde. Dissertação (Mestrado em Saúde Pública) - Rio de Janeiro: Escola Nacional de Saúde Pública Sergio Arouca, Fundação Oswaldo Cruz, 1994.

Ementas: Curso básico de capacitação de Vigilância em Saúde do trabalhador \& Curso de preparação para multiplicadores para capacitação em Vigilância em Saúde do Trabalhador. Brasília/Rio de Janeiro: Cosat/Fiocruz, 2005. Mimeografado.

Saúde, trabalho e desenvolvimento sustentável: apontamentos para uma política de Estado. Tese (Doutorado Saúde Pública) - Rio de Janeiro: Escola Nacional de Saúde Pública Sergio Arouca, Fundação Oswaldo Cruz, 2007.

VASCONCELLOS, L. C. Fadel. e RIBEIRO, Fátima S. N. 1997. Investigação epidemiológica e intervenção sanitária em saúde do trabalhador: o planejamento segundo bases operacionais. Cadernos de Saúde Pública, Rio de Janeiro, v. 13, n.2, p. 269-275, 1997.

Recebido em 09/02/2009

Aprovado em 11/08/2009 